\title{
How do external factors contribute to the hypocoagulative state in trauma-induced coagulopathy? - In vitro analysis of the lethal triad in trauma
}

Michael Caspers ${ }^{1,2^{*}}$ (D), Nadine Schäfer ${ }^{1}$, Matthias Fröhlich², Ursula Bauerfeind ${ }^{3}$, Bertil Bouillon ${ }^{2}$, Manuel Mutschler ${ }^{2}$ and Marc Maegele $e^{1,2}$

\begin{abstract}
Background: External factors following trauma and iatrogenic intervention influence blood coagulation and particularly clot formation. In particular, three external factors (in detail dilution via uncritical volume replacement, acidosis and hypothermia), in combination, referred to as the "lethal triad", substantially aggravate the hypocoagulative state after trauma. Contribution of these external factors to the resulting hypocoagulative state in trauma and especially their influence on primary haemostasis has still not been investigated systematically.

This study aims to assess this contribution to the aggravating hypocoagulative state in trauma-induced coagulopathy (TIC) using an in vitro simulation assay. Emphasis is given to platelet contribution to clot formation and to the investigation of how platelet activation alters under the respective conditions.

Methods: To simulate the conditions of lethal triad in vitro, whole blood samples taken from five healthy volunteers were introduced to the respective conditions. Besides standard coagulation testing, thrombelastometric analysis and differentiated platelet mapping were performed.

Results: All three simulated conditions induced significant impairments of clot formation (clot formation time, CFT; a -angle) and propagation (maximum clot firmness, MCF; Diameter A5-A25), with the highest impact under hypothermia and dilution. Consistently, lethal triad resulted in an additive effect of all conditions. None of the simulated conditions induced a statistically relevant change in coagulation initiation assessed by EXTEM and FIBTEM thrombelastometry. Platelet contribution to clot formation decreased gradually under the respective conditions, reaching statistical significance for simulated dilution, and attaining its greatest extent under the conditions of lethal triad $(\Delta$ trias/baseline 0.59; $p=0.01$ ). Consistent, reduced CD62 expression levels were observed under experimental acidosis ( $\Delta$ acidosis/ baseline 0.32; $p=0.006$ ), dilution ( $\Delta$ dilution/baseline $0.34 ; p=0.01$ ) and lethal triad ( $\Delta$ lethal triad/baseline $0.24 ; p=0.01$ ).

\footnotetext{
* Correspondence: michael.caspers@uni-wh.de

${ }^{1}$ The Institute for Research in Operative Medicine, Faculty of Health

Department of Medicine, Witten/Herdecke University, Ostmerheimer Str. 200,

51109 Cologne, Germany

${ }^{2}$ Department of Traumatology, Orthopaedic Surgery and Sports

Traumatology, Cologne-Merheim Medical Centre (CMMC), Witten/Herdecke

University, Campus Cologne-Merheim, Ostmerheimer Str. 200, 51109

Cologne, Germany

Full list of author information is available at the end of the article
}

(c) The Author(s). 2018 Open Access This article is distributed under the terms of the Creative Commons Attribution 4.0 International License (http://creativecommons.org/licenses/by/4.0/), which permits unrestricted use, distribution, and reproduction in any medium, provided you give appropriate credit to the original author(s) and the source, provide a link to the Creative Commons license, and indicate if changes were made. The Creative Commons Public Domain Dedication waiver (http://creativecommons.org/publicdomain/zero/1.0/) applies to the data made available in this article, unless otherwise stated. 


\begin{abstract}
(Continued from previous page)
Conclusion: The respective external factors of lethal triad play a pivotal role in the development of coagulopathy, essentially influencing the kinetics of clot formation, and to a varying extent clot diameter, as measured by thrombelastometry. Moreover, impairment of platelet function under the conditions of lethal triad plays a key role in the pathophysiology of TIC, resulting in reduced responsiveness to stimulation with ADP that might also be present after trauma. Our data indicate that impairment of primary haemostasis contribute to the hypocoagulative state in TIC after trauma aggravated by external factors of lethal triad.
\end{abstract}

Keywords: Lethal triad, Hypothermia in trauma, Acidosis in trauma, Dilution in trauma, ROTEM ${ }^{\circ}$, PlateletMapping ${ }^{\circ}$

\section{Background}

Haemorrhage after major traumatic injury is still the major global cause of lost life years [1-4]. On admission, one-quarter of trauma patients suffer from a "trauma-induced coagulopathy (TIC)" associated with massive blood loss and a higher incidence of multiple organ dysfunction, resulting in fourfold higher mortality $[5,6]$. Despite a profound upregulation in procoagulant mechanisms shortly after trauma, the main triggers for TIC have been identified as hypoperfusion, including hyperfibrinolysis, endothelial activation and platelet dysfunction, resulting in a primary and independent entity [5, 7-9]. In the further sequalae, this entity is substantially aggravated by iatrogenic interventions such as uncritical volume resuscitation leading to haemostatic depletion via dilution, acidosis and hypothermia, which, in combination, are referred to as the "lethal triad" [10]. Each condition contributes to a vicious and progressively worsening cycle, aggravating coagulopathy and resulting in a severely deleterious state for the trauma patient.

In contrast, coagulation analysis in trauma based on standard laboratory assays is hindered due to its methodological composition, as this does not reflect lethal triad conditions [11]. In addition, the validity of abnormalities in laboratory-based coagulation testing and their significance to a clinically relevant bleeding phenotype is still unclear as there is still an insufficient evidence that abnormal coagulation test results predict reliable a bleeding phenotype [12].

For viscoelastic assays, such as thromboelastometry, it could be shown that they enable a rapid evaluation of the patients' coagulation status after hospital admission and can therefore be used as point-of-care (POC) technology. Thromboelastometry provides information about primary haemostasis and enzyme function after trauma, and its use is therefore recommended by current guidelines $[13,14]$. But even though this technique has the potential to reflect the influence of external conditions on coagulation function, neither the contribution to coagulopathy of respective lethal triad factors in trauma, nor their combination, nor how they alter thrombelastometric testing have been investigated systematically.

In the present study, we aim to characterize the role of selected external factors reflecting the lethal clinical triad on clot initiation, dynamics and stability by using in vitro simulations. This approach allows the assessment of influences contributing to the lethal triad from different perspectives under standardized conditions, independent of physiological responses initiated rapidly to tissue injury and shock. The aim is to investigate both the influence of the respective condition on different phases of coagulation (plasmatic or platelet-based), and their combined affects. An emphasis has been given to the platelet contribution to clot formation and to the investigation of how platelet activation is altered under the respective conditions.

\section{Methods}

\section{Volunteers and collection of whole blood samples}

After the approval of the ethical committee of the University of Witten/Herdecke and in accordance with the Declaration of Helsinki, six healthy volunteers gave their written and informed consent to participating in this study. None of the donors had a medical history with respect to coagulopathy, a known bleeding disorder, or a treatment with any medication in the 10 days prior to the donation. One volunteer was excluded due to a pre-existing reduced platelet count $(<200.000 / \mu \mathrm{l})$ along with a reduced haematocrit. A whole blood sample of $450 \mathrm{ml}$ was then taken from each volunteer using a commercially available system containing $63 \mathrm{ml} \mathrm{CPD} \mathrm{(citrate-phosphate-dextrose-derivate)} \mathrm{and}$ $100 \mathrm{ml}$ mannitol for conservation and coagulation inhibition (composelect 4F T\&B-63 CPD/100 ml SAG-M-WB + PDS-M, ChBNo:41IB14FA00, Fresenius Kabi Deutschland GmbH, Bad Homburg, Germany; www.fresenius-kabi.de). To standardize the initial $\mathrm{pH}$ (median 7.35, IQR 0.02), sodium hydrogen carbonate (Sodiumhydrogencarbonat 8.4\%- B. Braun Infusionslösung, B.Braun Melsungen AG, Melsungen, Germany; www.bbraun.de) was added to the whole blood sample. After donation, samples were immediately aliquoted and introduced to the in vitro testing system using different sample tubes for the respective testing system (Blood count: 2,7 ml EDTA (1.6 mg EDTA/ $\mathrm{ml})$, S-Monovette, Sarstedt, Germany; Standard Coagulation/ROTEM ${ }^{\circ} /$ ROTEG $^{\circ}: 3 \mathrm{ml}$ 9NC (9NC: $0.106 \mathrm{~mol} / \mathrm{l}, \mathrm{S}$-Monovette, Sarstedt, Germany; BGA: $2 \mathrm{ml}$ LH (50 I.E. Heparin/ml Blood), S-Monovette, Sarstedt, Germany. 


\section{Lethal triad in vitro model}

In order to simulate conditions of lethal triad, the whole blood sample was separated into five equal vials that were kept at $37{ }^{\circ} \mathrm{C}$ in constant movement. Within all samples, temperature and $\mathrm{pH}$ were measured on a continuous basis (pH 3310, WTW GmbH, Weilheim, Germany, Serial No. 15340435). Acting as a baseline sample, vial 1 did not undergo any further treatment. Conditions of lethal triad were chosen based on clinical reports indicating coagulopathy introduced by lowering $\mathrm{pH}<7.0$ [15], dilution up to $33 \%$ [16] and hypothermia to $32{ }^{\circ} \mathrm{C}$ [17]. Introducing the respective conditions, $\mathrm{pH}$ was lowered to $\mathrm{pH} 6.8 \pm 0.05$ using $2 \mathrm{M} \mathrm{HCl}$ by titration (vial 2, "acidosis"), the blood samples were diluted to $33 \%$ using crystalloids (vial 3, "dilution"; Sterofundin ISO Infusionslösung, B. Braun Melsungen AG, Melsungen, Germany, www.bbraun.de) or temperature was lowered to $32{ }^{\circ} \mathrm{C}$ (vial 4, "hypothermia"). Vial 5 (lethal triad) combined all three external factors by lowering the temperature to $32{ }^{\circ} \mathrm{C}$ and $\mathrm{pH}$ to 6.8 and diluting the sample to $33 \%$. For excluding haemolysis, we measured free haemoglobin and the electrolytes $\mathrm{Na}^{+}, \mathrm{K}^{+}$, $\mathrm{Ca}^{2+}$ and $\mathrm{Cl}^{-}$by blood gas analysis (BGA, GEM 3500, Serial No. 14074200) for each sample. Following this, a differentiated coagulation testing including Activated Partial Thromboplastin Time (aPTT) [s], Thrombin Time [s], Quick [\%], INR [dimensionless], and fibrinogen [mg/dl] (via Clauss method), a standard blood count with haemoglobin $[\mathrm{g} / \mathrm{dl}]$, platelets count $[/ \mu \mathrm{l}]$, haematocrit [\%], a ROTEM analysis, a ROTEG platelet Mapping, and a platelet function testing was performed.

\section{ROTEM analysis}

Rotational thrombelastometry (ROTEM', Tem International $\mathrm{GmbH}$, Munich, Germany) was used according to the manufacturer's recommendations. Citrated blood samples were recalcified by adding $20 \mu \mathrm{l}$ of $\mathrm{CaCl}_{2}$ and introduced to EXTEM and FIBTEM assay. Data were collected for the following variables: coagulation time (CT), clot formation time (CFT), $\alpha$-angle, maximum clot firmness (MCF) and clot firmness after 5 (A5), 15 (A15) and 25 min (A25).

\section{PlateletMapping}

Thromboelastography analysis was performed with the ROTEG $^{\mathrm{TM}}$ Coagulation Analyzer (Haemonetics, Munich, Germany; www.haemonetics.de) using an ADP-PlateletMap ping Assay according to the manufacturer's instructions. Platelet aggregation in response to ADP was calculated on the basis of the formula: \% aggregation $=\left[\left(\mathrm{MA}_{\mathrm{ADP}}-\mathrm{MA}_{\text {fibrin }}\right) /\left(\mathrm{MA}_{\text {thrombin }}-\mathrm{MA}_{\text {fibrin }}\right)\right] \times 100$.

\section{Platelet function testing}

For platelet function testing, we used a kit provided by PlateletSolutions (Nottingham, UK, www.plateletsolutions.co.uk/products). Whole blood samples collected into sodium citrate tubes were introduced to the respective conditions of lethal triad. Samples were incubated for $5 \mathrm{~min}$ without mixing at the respective temperature and then fixed using PAMFix (Platelet Solutions Ltd., Nottingham, UK). For platelet stimulation, blood samples were treated with saline to provide a baseline test (baseline), ADP supplemented with U46619, (ADP/U4 $10 \mu \mathrm{M}$ and $1 \mu \mathrm{M}$ respectively ADP) or with $20 \mu \mathrm{M}$ thrombin receptor activating peptide (TRAP). Samples were then routinely analysed within 7 days by measuring expression of CD62 on thrombocytes using a flow-cytometric assay.

\section{Statistical analysis}

Descriptive results are presented as median and interquartile range (IQR). Nonparametric Kruskal-Wallis test was performed to compare changes in laboratory data when comparing respective condition vs. baseline. All aggregated values are presented in mean and standard deviation and multiple students' t-tests were performed when comparing condition vs. baseline or lethal triad vs. baseline. To test for normal distribution, the Shapiro-Wilk-test was performed. Results are described as "statistically significant" if their error probability was less than $5 \%(p<0.05)$.

Statistical analyses were performed using GraphPad Prism version 7.00 for Windows (GraphPad Software, La Jolla California USA).

\section{Results \\ Standard coagulation assays and blood count}

Untreated blood samples obtained at baseline and assessed by using standard coagulation assays and blood count revealed values within physiological reference ranges as shown in Table 1. The exposure of blood samples to experimental acidosis and hypothermia was not associated with any significant changes in either standard coagulation assays or blood count. However, when blood samples were exposed to experimental 33\% dilution, haemoglobin, haematocrit, platelets and fibrinogen concentration dropped by approximately one third, with a corresponding change in standard coagulation assays by $20-30 \%$. The exposure to the combination of all three conditions ("lethal triad") was associated with a further drop in platelets along with a slight further increase in prothrombin time (Table 1).

\section{Clot initiation and formation}

EXTEM CTs in blood samples exposed to all three conditions remained unchanged as compared to baseline. In contrast, all conditions were associated with significant changes in EXTEM CFTs and $\alpha$-angles, reflecting impaired clot dynamics (EXTEM CFT LT/WB $=3.42 \mathrm{~s} ; p=0.0008$; EXTEM $\alpha$-angle $/ \mathrm{WB}=0.67^{\circ} ; p=0.004$; Fig. 1a). This phenomenon 
Table 1 Standard blood count and cougulation testing for the respective lethal triad conditions

\begin{tabular}{|c|c|c|c|c|c|c|c|c|}
\hline & Blood count & & & Standard & ulation test & & & BGA \\
\hline & $\begin{array}{l}\text { Haemoglobin } \\
\text { level }[\mathrm{g} / \mathrm{dl}]\end{array}$ & $\begin{array}{l}\text { Platelets } \\
{[10 \wedge 3 / \mu l]}\end{array}$ & $\begin{array}{l}\text { Haematocrit } \\
{[\%]}\end{array}$ & $\mathrm{aPTT}[\mathrm{s}]$ & $\pi[s]$ & INR & $\begin{array}{l}\text { Fibrinogen } \\
{[\mathrm{mg} / \mathrm{dl}]}\end{array}$ & $\mathrm{pH}$ \\
\hline Baseline & $11.4(0.3)$ & 257 (103) & $32.7(2.5)$ & $30.3(0.3)$ & $16(0.3)$ & $1.18(0.1)$ & 250 (59) & $7.35(0.02)$ \\
\hline $\mathrm{pH} 6.8$ & $12.6(1.4)$ & 211 (70) & $35.4(3.1)$ & $27.5(0.3)$ & $17.5(0.3)$ & $1.14(0.09)$ & 268 (39) & $6.83(0.05)$ \\
\hline Temp. $33^{\circ} \mathrm{C}$ & $11.4(1)$ & 247 (98) & 33.1 (2.3) & $32.1(0.1)$ & $15.7(0.1)$ & $1.16(0.13)$ & $243(62)$ & $7.38(0.00)$ \\
\hline Dilution & $7.5(0.9)$ & $167(44)$ & $22.2(2.3)$ & $43.3(0.6)$ & $20.8(0.6)$ & $1.41(0.07)$ & 166 (39) & $7.37(0.02)$ \\
\hline Lethal Triad & $7.7(0.8)$ & 125 (59) & $22.8(2)$ & $34.9(0.8)$ & $23.8(0.8)$ & $1.46(0.11)$ & $154(27)$ & $6.83(0.02)$ \\
\hline
\end{tabular}

Left column: Results from standard blood count for the respective conditions, including haemoglobin level [g/dl], platelet count [/ $\mu$ l] and haematocrit [\%]. Right column: Results from standard coagulation testing, including Activated Partial Thromboplastin Time (aPTT) [s], Thrombin Time [s], Quick [\%], INR [dimensionless] and fibrinogen level measured via Clauss method [mg/dl]. Right column: $\mathrm{pH}$ values measured at respective time points

All results are given as median values. The Interquartile Range (IQR) is given in brackets

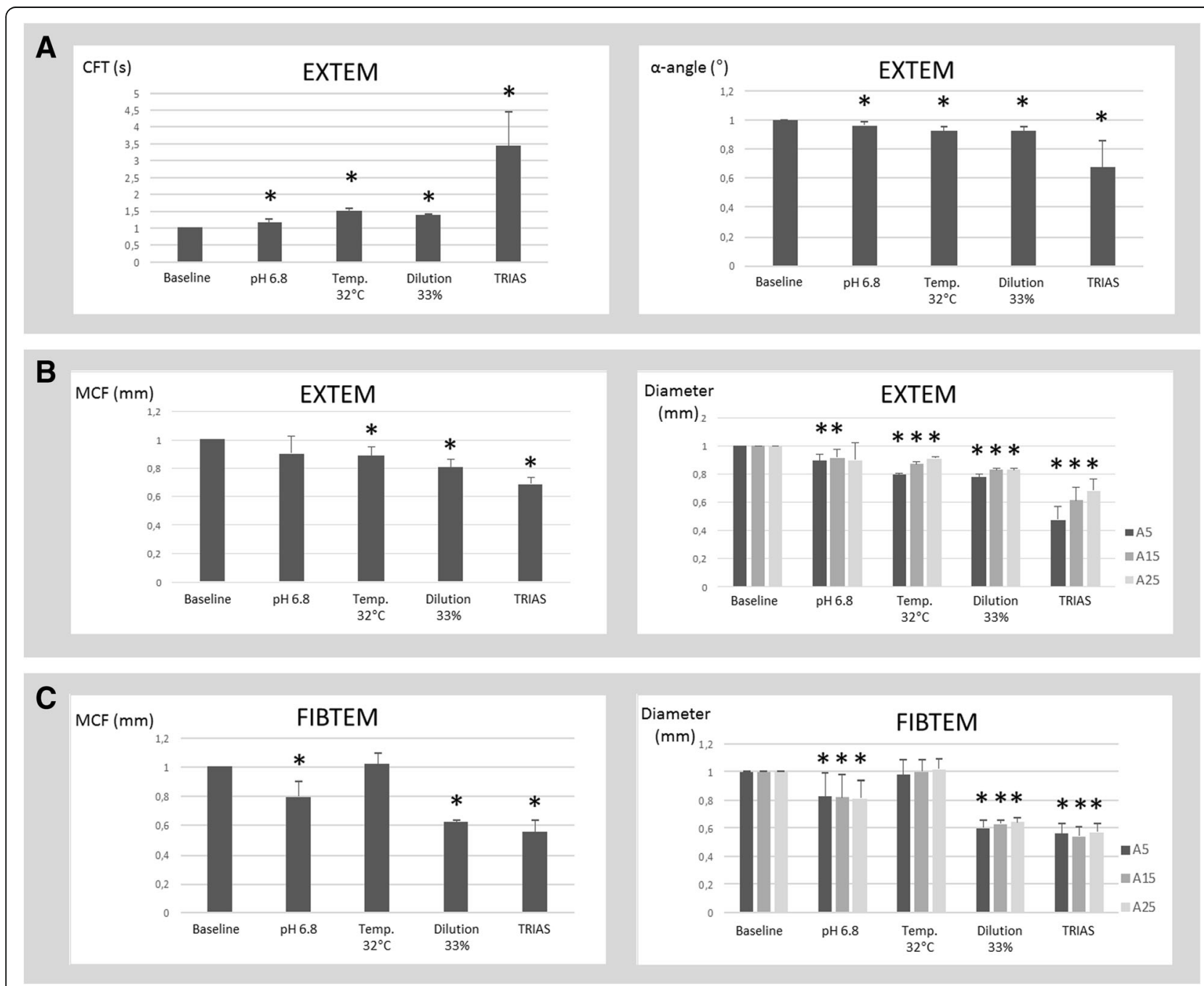

Fig. 1 Clot kinetics and clot formation in ROTEM ${ }^{\circ}$. Functional coagulation testing using ROTEM analysis is presented as relative changes referring to the respective baseline coagulation. Baseline coagulation is set as 100\%, respectively. Results are marked as statistically significant if their error probability was less than $5 \%\left(p<0.05 ;{ }^{*}\right)$. a: Clot kinetics in EXTEM, specified by CFT and a-angle. b: Clot formation in EXTEM, specified by MCF and clot diameter after 5 min (A5), $15 \mathrm{~min}$ (A15) and $25 \mathrm{~min}$ (A25). c: Clot formation in FIBTEM, specified by MCF and clot diameter after 5 min (A5), 15 min (A15) and 25 min (A25) 
was most pronounced when all three conditions were combined in the lethal triad preparation.

Assessing clot formation, EXTEM MCF decreased under the given conditions in the ranked order acidosis $<$ hypothermia<dilution. Under lethal triad condition, the greatest impact on clot diameter was observed (EXTEM MCF LT/WB $=0.69 p<0.0001$ ). Interestingly, under conditions of lethal triad, we found a stronger impact on clot firmness for early time points (EXTEM A5) compared with late (EXTEM A25), resulting in a higher gradient of increasing clot size over time (c.f. Fig. 1b). In contrast, early FIBTEM time points (FIBTEM A5) were affected to the same extent compared to late (FIBTEM A25), without any significant relative clot assembly over time (Fig. 1c).

Accordingly, early and maximum FIBTEM amplitudes were significantly reduced under experimental acidosis, dilution and lethal triad, but not when exposed to isolated hypothermia. Exposure of blood samples to isolated acidosis was associated with a $20 \%$ decline in early and maximum FIBTEM clot amplitudes, while isolated dilution and combined lethal triad were associated with an almost 50\% decline in early and maximum FIBTEM clot amplitudes, reflecting substantially impaired clot stability under the given conditions (Fig. 1c).

\section{Platelet contribution and functional platelet analysis}

Platelet contribution to clot formation under the respective conditions was investigated comparing expression levels of CD62 on platelet surface at baseline and after stimulation with ADP or TRAP. Unstimulated expression gradually decreased under the given conditions, reaching statistical significance with experimental acidosis ( $\Delta$ acidosis/baseline $0.32 ; p=0.006)$, dilution ( $\Delta$ dilution/baseline $0.34 ; p=0.01$ ) and combined lethal triad ( $\Delta$ lethal triad/baseline $0.24 ; p=0.01$, Fig. $2 b$ ). In addition, reduced response after stimulation with ADP under lethal triad condition could be observed reaching similar values compared to the acidosis condition but only reaching statistical significance (Fig. 2b). For all other conditions, in case of stimulation with ADP or TRAP no significant change could be observed (Fig. 2b). This effect was confirmed by investigating the functional platelet contribution to clot formation using ROTEG $^{\circ}$ platelet mapping. Platelet contribution decreased gradually under the respective conditions, reaching statistical significance for simulated dilution, and attaining its greatest extent under the conditions of lethal triad ( $\Delta$ trias/baseline $0.59 ; p=0.01$, Fig. $2 \mathrm{a}$ ).

\section{Discussion}

The study aimed to elucidate the contribution of external factors - either isolated or combined in the context of the lethal triad - to the aggravating hypocoagulative state in TIC.

Based on the in vitro study design and a comprehensive coagulation analysis, interference of external triad factors in TIC and their impact on different pathways in coagulation were analysed.

\section{The lethal triad in TIC}

To date, only a few studies have focused on the interference of external triad factors, and none has investigated the combination of all three in vitro [18]. Under all three conditions, we observed an additive effect resulting in significantly impaired clot formation and propagation, along with reduced clot firmness. Interestingly, initiation of clotting as reflected by clotting times was neither disturbed under isolated nor under combined conditions.

\section{The role of acidosis in TIC}

Acidosis in trauma is mostly related to tissue hypoperfusion accompanied by an anaerobic metabolism, but may also result from resuscitation with chloride-containing fluids or blood stored in citrate phosphate dextrose adenine solution [19]. Acidosis has been shown to directly reduce coagulation capacity [20] via shifts in $\mathrm{pH}$ reaction optimum [15, 21, 22] and structural changes of coagulation factor $\mathrm{Ca}^{2+}$-binding sites [23]. A reduction in $\mathrm{pH}$ to 7.0 drops factor VIIa concentrations by $>90 \%$, the FIIa/tissue factor complex by $55 \%$, and the $\mathrm{FXa} / \mathrm{FVa}$ complex by $70 \%$, along with thrombin generation impairment [24]. In the present study, experimental acidosis was associated with thromboelastometric signs of impaired clot dynamics and stability. In a previous study, a $\mathrm{pH}$ reduction to 6.8 resulted in reduced clot stability, but also in prolonged clot initiation, which was not observed in the present study [25].

The most profound effect in the present study was observed in the FIBTEM assay, which reflects fibrin polymerization. As clot formation kinetics highly depend on the availability of fibrinogen and platelet function, it may be speculated that this effect was caused by fibrinogen dysfunction [18]. Experimental evidence suggests that acidosis increases fibrinogen breakdown by factor 1.8, with no impact on fibrinogen synthesis [26].

\section{The role of hypothermia in TIC}

Considering mild hypothermia to be therapeutically effective for neuroprotection, the potential impact of hypothermia on haemostasis is of particular interest [10, $27,28]$. For a long time, coagulopathy recognized under hypothermic conditions was hypothesized to result mainly from reduced protease activity of clotting enzymes [29]. However, several in vivo studies could not verify this effect under mild hypothermia, and concluded that the overall enzymatic process in haemostasis is not significantly affected by a reduction from normothermia 

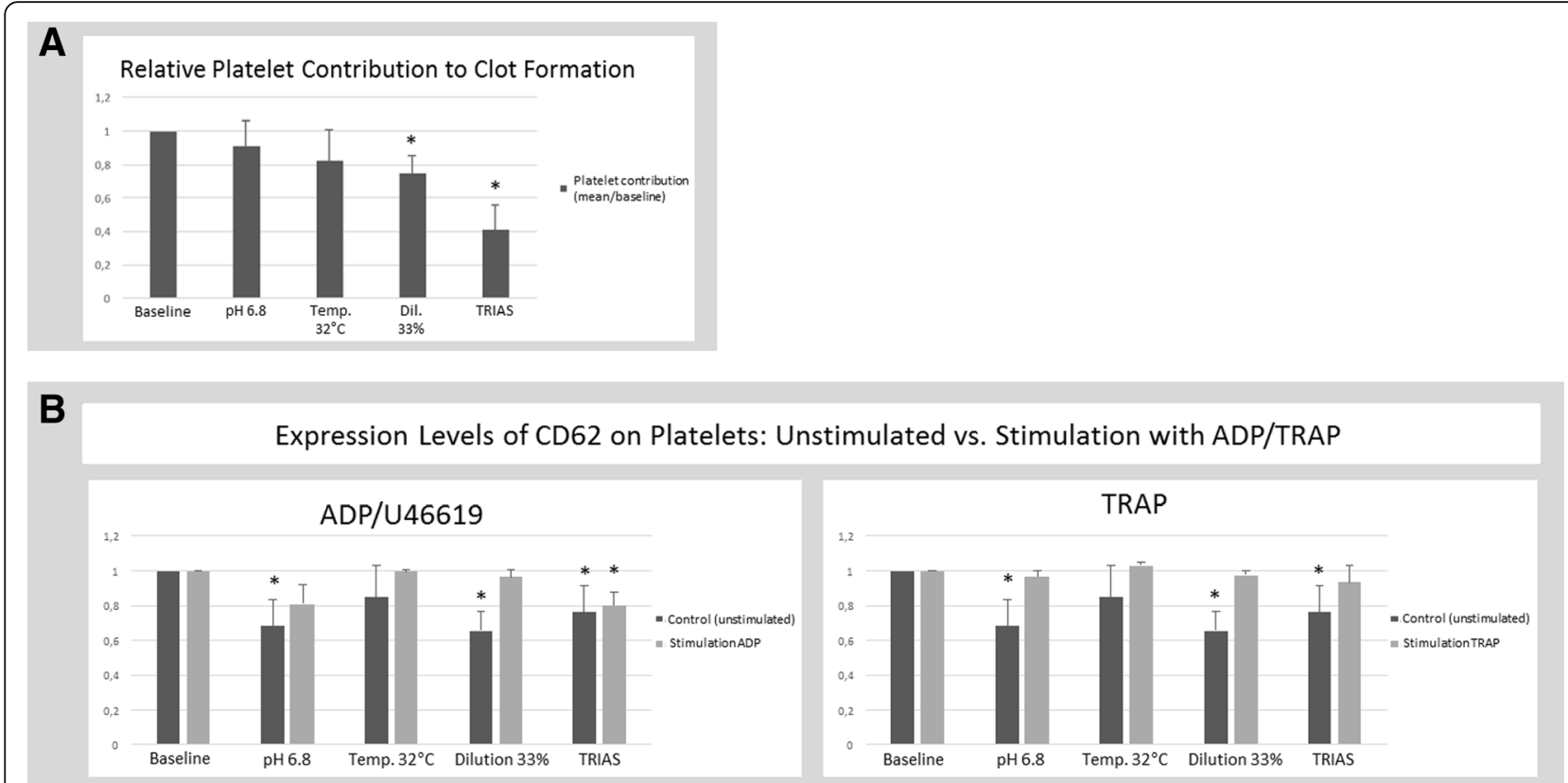

Fig. 2 Platelet contribution under condition of lethal triad. a: Functional analysis of platelet contribution to clot formation using ROTEG PlateletMapping. Results are presented as relative changes referring to the respective baseline (set as 100\%). Results are marked as statistically significant if error probability was less than $5 \%\left(p<0.05 ;{ }^{*}\right)$. b: Expression levels of CD62 on platelets surface are presented. Respectively, for each condition of lethal triad the expression levels unstimulated are shown (left column, c.f. "control, unstimulated") and expression levels after stimulation (right column) with ADP/U46619 (left diagram) and with TRAP (right diagram). Results are presented as relative changes referring to the respective baseline (set as 100\%). Results are marked as statistically significant if error probability was less than $5 \%\left(p<0.05\right.$; $\left.{ }^{*}\right)$

to $32{ }^{\circ} \mathrm{C}$ [30-32]. Furthermore, mild hypothermia does not seem to influence the clotting onset [33, 34]. These findings are consistent with our results obtained from standard coagulation assays, which essentially measure a sum of enzymatic steps, as well as from our viscoelastic test results assessing clotting times, which remained unaltered under the hypothermic conditions exposed in the present study. In contrast, clot dynamics in terms of CFTs and $\alpha$-angles were significantly altered when blood samples were exposed to hypothermia, and thus confirmed previous in vitro studies revealing a significant correlation between temperature and haemostasis, with lower temperatures leading to an impairment of coagulation $[11,35]$. Due to the fact that coagulation initiation reflects initial thrombin generation, and fibrin formation is mainly based on plasmatic proteases activity that is not impaired by hypothermia to such an extent as assumed, it may perhaps explain why only a slight tendency was observed for clot initiation times [36]. Considering clot stability parameters with the given reference ranges, fibrin polymerization may not, then, be affected by hypothermia.

\section{The role of dilution in TIC}

In the clinical scenario, uncritical prehospital volume resuscitation has been identified as an independent risk factor for impaired coagulation profiles on admission
[37]. In vitro studies revealed that dilution $>40 \%$ was required to induce coagulopathy [38], but retrospective registry data from trauma patients reported lower quantities as necessary to induce a bleeding phenotype with coagulopathy [16]. The experimental 33\% dilution model used in the present study confirmed prolonged clot formation and propagation, as well as reduced clot firmness. The reduction in clot amplitude in the FIBTEM assay corresponded to reduced quantitative fibrinogen concentrations after dilution.

\section{Platelet dysfunction in TIC}

Due to complexities in platelet testing, only a few studies have addressed platelet dysfunction in trauma and its contribution to TIC. However, near-total impairment of clot formation can occur as a result of platelet dysfunctions that are not detected by plasma-based coagulation testing [39]. The few studies that are available for platelet analysis in trauma use a variety of testing methods. To date, there has been no direct comparison of TEG-based platelet mapping with results from impedance aggregometry and direct measurement of CD62 expression using a flowcytometric assay. In this study, we used two different methods, but - quite apart from the fact that more research has to be done to elucidate the role of platelets in TIC - correlation of these different methods is of particular importance. 
The data we derived from ROTEG ${ }^{\circ}$ platelet mapping indicate a significant impaired responsiveness with greatest impact for dilution and lethal triad. No impact on ADP stimulation was seen under the condition of hypothermia, which is in line with recent findings by Xavier et al., who describe enhanced platelet aggregation and ability to stimuli with ADP under conditions of hypothermia [40]. It can be assumed that impairment under conditions of lethal triad indicates a cumulative effect.

Using the flow-cytometric assay, under conditions of lethal triad, almost no stimulation with ADP was observed, resulting in a higher expression rate which indicated that the ADP pathway plays an important role in mediating platelet dysfunction under these external factors.

Comparing 51 trauma patients with 39 healthy controls, Wohlhauer et al. found evidence for significant reduced contribution to clot formation after stimulation with ADP within their trauma group, which is in accordance with our results. This reduced responsiveness to ADP has been attributed to a desensitization following continued exposure to ADP that is known to result from tissue injury and hypoperfusion [41, 42]. This might also be an effect in trauma, revealing an acquired defect due to circulation of exhausted platelets following prolonged activation. Otherwise, our data additionally provides evidence that hyporesponsiveness to ADP stimulation is also affected by external conditions as present under TIC.

A retrospective analysis of 163 trauma patients (mean ISS of 18) by Solomon et al. reported platelet hyporesponsivness to ADP and TRAP stimulation, and values below the normal range were significantly more frequent in non-survivors than in survivors $(p=0.0017$ and $p=0.0002)$ [43].

Using a flow-cytometric assay to investigate ADP- and TRAP-mediated platelet aggregation response, Ramsey et al. found significantly lower levels of platelet activation and platelet function in 40 trauma patients (mean ISS of 10, IQR 2-18) compared to control subjects [44]. Based on the most significant reduction of TRAP, responsiveness in patients with head injuries, and the fact that TRAP served as a surrogate thrombin agonist, they suspect that thrombin-mediated activation of platelets via PAR-1 receptor may be restricted following an unknown pathomechanism. Whether this effect results from the particular entity of TBI, as some recent studies suggest, or could be attributed to a cross-link mechanism of platelet-coagulation within the trauma pathomechanism in TIC, has to be clarified in further studies $[44,45]$.

The present study has several limitations. In vitro settings are not able to fully reflect the pathophysiological mechanism present in trauma patients. Therefore, one should only cautiously extrapolate present findings to the setting presented in vivo or in a clinical situation. However, to isolate the respective conditions and to investigate the relevant interactions and their contribution to a resulting coagulopathy is not feasible in living human.

\section{Conclusion}

Our study continues to support the concept of TIC as an endogenous entity comprising all the components of haemostasis, which follows rapidly on tissue injury, hypoperfusion and haemorrhagic shock. In addition, secondary factors of the lethal triad contribute to a different extent to a hypocoagulative state and have a direct impact on clot formation and platelet function as measured by thrombelastometry. Hence impairment of platelet function plays a key role in the pathophysiology of TIC. Thrombelastometric testing enables rapid evaluation of coagulopathy introduced by external factors after trauma, in contrast to standard coagulation testing. Our data indicates that conditions of lethal triad have an independent effect on platelet function, resulting in platelet dysfunction and reduced responsiveness to stimulation with ADP that might also be present after trauma. Therefore, impairment in primary haemostasis after major trauma should be taken more into consideration and included in the methodological setting of coagulation analysis after trauma.

\section{Abbreviations \\ aPTT: Activated Partial Thromboplastin Time; BGA: Blood gas analysis; CFT: Clot formation time; CPD: Citrate-phosphate-dextrose-derivate; CT: Coagulation time; MCF: Maximum clot firmness; POC: Point-of-care; TIC: Trauma-induced coagulopathy; TRAP: thrombin receptor activating peptide}

\section{Acknowledgements}

Our special thank goes to Verena Köster, Wilma Groß-Holz and Arthur Camphausen for technical support. Furthermore, we would like to thank Ewa Stürmer for assistance in organizational issues.

\section{Funding}

This study was financially supported by the research funding of the University of Witten/Herdecke. An additional ROTEM delta ${ }^{\circ}$ had been provided by TEM International GmbH for this study.

\section{Availability of data and materials}

The datasets used and analysed during the current study are available from the corresponding author on reasonable request.

\section{Authors' contributions}

MC, NS, MF carried out the laboratory procedure. UB, BB and MM participated in the design and coordination of the study and helped to include blood donors to compose the in vitro assay. MC wrote the initial manuscript and performed the statistical analysis. All authors read and approved the final manuscript. MM conceived the study and supported the process as a senior author.

\section{Ethics approval and consent to participate}

Study design and protocol was approved by the Central Ethics Committee of the University Witten/Herdecke (no. 37/2005 and 168/2014).

\section{Consent for publication}

Six healthy volunteers (blood donors) gave their written and informed consent to participating in this study. 


\section{Competing interests}

Marc Maegele has received honoraria for lectures and traveller fees from TEM International. Other authors declare no conflict of interest.

\section{Publisher's Note}

Springer Nature remains neutral with regard to jurisdictional claims in published maps and institutional affiliations.

\section{Author details}

${ }^{1}$ The Institute for Research in Operative Medicine, Faculty of Health, Department of Medicine, Witten/Herdecke University, Ostmerheimer Str. 200, 51109 Cologne, Germany. ${ }^{2}$ Department of Traumatology, Orthopaedic Surgery and Sports Traumatology, Cologne-Merheim Medical Centre (CMMC), Witten/Herdecke University, Campus Cologne-Merheim, Ostmerheimer Str. 200, 51109 Cologne, Germany. ${ }^{3}$ Department of Transfusion Medicine, Cologne-Merheim Medical Centre (CMMC), Witten/ Herdecke University, Campus Cologne- Merheim, Ostmerheimer Str. 200, 51109 Cologne, Germany.

\section{Received: 28 April 2018 Accepted: 6 August 2018}

\section{Published online: 15 August 2018}

\section{References}

1. Evans JA, Van Wessem KJP, McDougall D, Lee KA, Lyons T, Balogh ZJ. Epidemiology of traumatic deaths: comprehensive population-based assessment. World J Surg. 2010;34:158-63.

2. Gruen RL, Jurkovich GJ, McIntyre LK, Foy HM, Maier RV. Patterns of errors contributing to trauma mortality: lessons learned from 2,594 deaths. Ann Surg. 2006;244:371-80. https://doi.org/10.1097/01.sla.0000234655.83517.56.

3. Sauaia A, Moore FA, Moore EE, Moser KS, Brennan R, Read RA, et al. Epidemiology of trauma deaths: a reassessment. J Trauma. 1995;38:185-93.

4. Schochl H, Frietsch T, Pavelka M, Jambor C. Hyperfibrinolysis after major trauma: differential diagnosis of lysis patterns and prognostic value of thrombelastometry. J Trauma. 2009;67:125-31. https://doi.org/10.1097/TA. Ob013e31818b2483.

5. Brohi K, Singh J, Heron M, Coats T. Acute traumatic coagulopathy. J Trauma. 2003;54:1127-30. https://doi.org/10.1097/01.TA.0000069184.82147.06.

6. MacLeod JB a, Lynn M, McKenney MG, Cohn SM, Murtha M. Early coagulopathy predicts mortality in trauma. J Trauma 2003;55:39-44. doi: https://doi.org/10.1097/01.TA.0000075338.21177.EF.

7. Ganter MT, Brohi K, Cohen MJ, Shaffer LA, Walsh MC, Stahl GL, et al. Role of the alternative pathway in the early complement activation following major trauma. Shock. 2007;28:29-34. https://doi.org/10.1097/shk. ob013e3180342439.

8. Johansson PI, Stensballe J, Rasmussen LS, Ostrowski SR. A high admission syndecan-1 level, a marker of endothelial glycocalyx degradation, is associated with inflammation, protein C depletion, fibrinolysis, and increased mortality in trauma patients. Ann Surg. 2011;254:194-200. https:// doi.org/10.1097/SLA.0b013e318226113d.

9. Johansson PI, Stensballe J, Rasmussen LS, Ostrowski SR. High circulating adrenaline levels at admission predict increased mortality after trauma. J Trauma Inj Infect Crit Care. 2011;72:1. https://doi.org/10.1097/TA. Ob013e31821eof93.

10. SE M. Hypothermia in trauma. Emerg Med J 2013;30:989-996:989-996. doi: https://doi.org/10.1136/emermed-2012-201883.

11. Dirkmann D, Goerlinger K, Peters J. Assessment of early thromboelastometric variables from extrinsically activated assays with and without aprotinin for rapid detection of fibrinolysis. Anesth Analg. 2014;119: 533-542. doi:https://doi.org/10.1213/ANE.0000000000000333.

12. Lier $\mathrm{H}$, Krep H, Schroeder S, Stuber F. Preconditions of hemostasis in trauma: a review. The influence of acidosis, hypocalcemia, anemia, and hypothermia on functional hemostasis in trauma. J Trauma. 2008;65:951-60. https://doi. org/10.1097/TA.0b013e318187e15b.

13. Rossaint R, Bouillon B, Cerny V, Coats TJ, Duranteau J, Fernández-Mondéjar $E$, et al. The European guideline on management of major bleeding and coagulopathy following trauma: fourth edition. Crit Care. 2016;20:100. https://doi.org/10.1186/s13054-016-1265-x.

14. S3 - Leitlinie Polytrauma/ Schwerverletzten-Behandlung. Http://www. awmf.org n.d.

15. Meng ZH, Wolberg AS. Monroe 3rd DM, Hoffman M. The effect of temperature and $\mathrm{pH}$ on the activity of factor Vlla: implications for the efficacy of high-dose factor Vlla in hypothermic and acidotic patients. J Trauma. 2003:55:886-91. https://doi.org/10.1097/01.TA.0000066184.20808.A5.

16. Maegele M, Lefering $R$, Yucel N, Tjardes T, Rixen D, Paffrath T, et al. Early coagulopathy in multiple injury: an analysis from the German trauma registry on 8724 patients. Injury. 2007;38:298-304. https://doi.org/10.1016/j. injury.2006.10.003.

17. Jurkovich G, Greiser W, Luterman A, Curreri P. Hypothermia in trauma victims: an ominous predictor of survival. J Trauma Acute Care Surg. 1987;27

18. Dirkmann D, Hanke AA, Görlinger K, Peters J. Hypothermia and acidosis synergistically impair coagulation in human whole blood. Anesth Analg. 2008;106:1627-32. https://doi.org/10.1213/ane.0b013e31817340ad.

19. Noel P, Cashen S, Patel B. Trauma-induced coagulopathy: from biology to therapy. Semin Hematol. 2013;50:259-69. https://doi.org/10.1053/j. seminhematol.2013.06.009.

20. Green FW, Kaplan MM, Curtis LE, Levine PH. Effect of acid and pepsin on blood coagulation and platelet aggregation. A possible contributor prolonged gastroduodenal mucosal hemorrhage. Gastroenterology. 1978;74:38-43.

21. Martinowitz U, Michaelson M. Guidelines for the use of recombinant activated factor VII (rFVIla) in uncontrolled bleeding: a report by the Israeli multidisciplinary rFVIla task force. J Thromb Haemost. 2005;3:640-8. https:// doi.org/10.1111/j.1538-7836.2005.01203.x.

22. Martini WZ, Dubick M a, Pusateri AE, Park MS, Ryan KL, Holcomb JB. Does bicarbonate correct coagulation function impaired by acidosis in swine? J Trauma 2006;61:99-106. doi:https://doi.org/10.1097/01.ta.0000215574.99093.22.

23. Suzuki N, Fujimoto Z, Morita T, Fukamizu A, Mizuno H. pH-dependent structural changes at Ca2+-binding sites of coagulation factor IX-binding protein. J Mol Biol. 2005;353:80-7. https://doi.org/10.1016/j.jmb.2005.08.018.

24. Meng $\mathrm{ZH}$, Wolberg AS, Monroe DM, Hoffman M. The effect of temperature and $\mathrm{pH}$ on the activity of factor Vlla: implications for the efficacy of highdose factor VIla in hypothermic and acidotic patients. J Trauma. 2003:55: 886-91. https://doi.org/10.1097/01.TA.0000066184.20808.A5

25. Engström M, Schött U, Romner B, Reinstrup P. Acidosis impairs the coagulation: a thromboelastographic study. J Trauma. 2006;61:624-8. https://doi.org/10.1097/01.ta.0000226739.30655.75.

26. Martini WZ, Holcomb JB. Acidosis and coagulopathy: the differential effects on fibrinogen synthesis and breakdown in pigs. Ann Surg. 2007;246:831-5. https://doi.org/10.1097/SLA.0b013e3180cc2e94.

27. Nathan $\mathrm{HJ}$, Polis T. The management of temperature during hypothermic cardiopulmonary bypass: I--Effect of prolonged hypothermia . Can J Anaesth = J Can D'anesthésie 1995;42:672-6. doi:https://doi.org/10.1007/BF03012663.

28. Tsuei BJ, Kearney PA. Hypothermia in the trauma patient. Injury. 2004;35:715. https://doi.org/10.1016/S0020-1383(03)00309-7.

29. von Kaulla KNSH. Clotting deviations in man associated with open-heart surgery during hypothermia. J Thorac Surg. 1958;36(36):857-68.

30. Wolberg AS, Meng ZH. Monroe 3rd DM, Hoffman M. A systematic evaluation of the effect of temperature on coagulation enzyme activity and platelet function. J Trauma. 2004:56:1221-8.

31. Johnston TD, Chen $Y$, Reed RL. Functional equivalence of hypothermia to specific clotting factor deficiencies. J Trauma. 1994:37:413-7.

32. Mohr J, Ruchholtz S, Hildebrand F, Flohé S, Frink M, Witte I, et al. Induced hypothermia does not impair coagulation system in a swine multiple trauma model. J Trauma Acute Care Surg. 2013;74:1014-20. https://doi.org/ 10.1097/TA.0b013e3182826edd.

33. Reed RL, Johnson TD, Hudson JD, Fischer RP. The disparity between hypothermic coagulopathy and clotting studies. J Trauma. 1992:33:465-70. https://doi.org/10.1097/00005373-199209000-00022.

34. Gubler KD, Gentilello LM, Hassantash SA, Maier RV. The impact of hypothermia on dilutional coagulopathy. J Trauma. 1994;36:847-51. https:// doi.org/10.1097/00005373-199406000-00015.

35. Rundgren $M$, Engström M. A thromboelastometric evaluation of the effects of hypothermia on the coagulation system. Anesth Analg. 2008;107:1465-8. https://doi.org/10.1213/ane.0b013e31817ee955.

36. Winstedt D, Thomas OD, Nilsson F, Olanders K, Schött U. Correction of hypothermic and dilutional coagulopathy with concentrates of fibrinogen and factor XIII: an in vitro study with ROTEM. Scand J Trauma Resusc Emerg Med. 2014;22:73. https://doi.org/10.1186/s13049-014-0073-z.

37. Wafaisade A, Wutzler S, Lefering R, Tjardes T, Banerjee M, Paffrath T, et al. Drivers of acute coagulopathy after severe trauma: a multivariate analysis of 1987 patients. Emerg Med J. 2010;27:934-9. https://doi.org/10.1136/emj.2009.088484.

38. Brazil EV, Coats TJ. Sonoclot coagulation analysis of in-vitro haemodilution with resuscitation solutions. J R Soc Med. 2000;93:507-10. 
39. Kutcher ME, Redick BJ, McCreery RC, Crane IM, Greenberg MD, Cachola LM, et al. Characterization of platelet dysfunction after trauma. J Trauma Acute Care Surg. 2012;73:13-9. https://doi.org/10.1097/TA.0b013e318256deab.

40. Xavier RG, White AE, Fox SC, Wilcox RG, Heptinstall S. Enhanced platelet aggregation and activation under conditions of hypothermia. Thromb Haemost. 2007;98:1266-75. https://doi.org/10.1160/TH07-03-0189.

41. Baurand A, Eckly A, Bari N, Leon C, Hechler B, Cazenave JP, et al. Desensitization of the platelet aggregation response to ADP: differential down-regulation of the P2Y1 and P2cyc receptors. Thromb Haemost. 2000;84:484-91.

42. Bune LT, Thaning P, Johansson PI, Bochsen L, Rosenmeier JB. Effects of nucleotides and nucleosides on coagulation. Blood Coagul Fibrinolysis. 2010;21:436-41. https://doi.org/10.1097/MBC.0b013e328338db27.

43. Solomon C, Traintinger S, Ziegler B, Hanke A, Rahe-Meyer N, Voelckel $W$, et al. Platelet function following trauma; a multiple electrode aggregometry study. Thromb Haemost. 2011;106:322-30. https://doi.org/ 10.1160/TH11-03-0175.

44. Ramsey MT, Fabian TC, Shahan CP, Sharpe JP, Mabry SE, Weinberg JA, et al. A prospective study of platelet function in trauma patients. J Trauma Acute Care Surg. 2016;80:726-33. https://doi.org/10.1097/TA.0000000000001017.

45. Nekludov M, Bellander B-M, Blombäck M, Wallen HN. Platelet dysfunction in patients with severe traumatic brain injury. J Neurotrauma. 2007;24:1699-706. https://doi.org/10.1089/neu.2007.0322.

Ready to submit your research? Choose BMC and benefit from:

- fast, convenient online submission

- thorough peer review by experienced researchers in your field

- rapid publication on acceptance

- support for research data, including large and complex data types

- gold Open Access which fosters wider collaboration and increased citations

- maximum visibility for your research: over $100 \mathrm{M}$ website views per year

At BMC, research is always in progress.

Learn more biomedcentral.com/submissions 